УДК 378.014.23(47+57)(597)

\title{
ПРАКТИКИ ЭКСПОРТА ОБРАЗОВАТЕЛЬНЫХ УСЛУГ РОССИЙСКИХ ВУЗОВ В СОЦИАЛИСТИЧЕСКУЮ РЕСПУБЛИКУ ВЬЕТНАМ
}

\author{
Голомидова Полина Сергеевна, \\ polinagolomidova@gmail.com

\begin{abstract}
Северный (Арктический) федеральный университет имени М.В. Ломоносова, Россия, 163002, г. Архангельск, наб. Северной Двины, 17
\end{abstract}

Голомидова Полина Сергеевна, аспирант кафедры философии и социологии, начальник отдела рекрутинга Управления международного сотрудничества Северного (Арктического) федерального университета имени М.В. Ломоносова.

\begin{abstract}
Актуальность. Растущее значение международной студенческой миграции связано не только с увеличением числа иностранных студентов по всему миру, но и с ростом политического, экономического и культурного влияния данных процессов, а также с целенаправленной деятельностью стран-экспортеров и вузов по продвижению образовательных программ за рубеж. Одной из наиболее перспективных стран в сфере экспорта образования является Социалистическая Республика Вьетнам (СРВ), находящаяся на восходящем тренде исходящей академической мобильности. Цель статьи - представить результаты исследования лучших практик и используемых российскими вузами инструментов по привлечению студентов из Социалистической Республики Вьетнам. Методология. В рамках проведенного анализа статистических данных Центра социологических исследования Минобрнауки России, Института статистики ЮНЕСКО, анализа открытых источников в сети Интернет и включенного наблюдения в процессе профессиональной деятельности автора были выявлены академические и маркетинговые мероприятия, а также различные форматы взаимодействия со студентами, выпускниками, вьетнамскими организациями и российскими организациями, работающими в СРВ. По результатам исследования установлено, что все изучаемые университеты используют сочетание различных практик, диверсифицируя инструменты рекрутинга и развивая широкое научно-образовательное сотрудничество с Вьетнамом. Были выявлены следующие практики, способствующие успешному привлечению вьетнамских студентов в конкретные образовательные учреждения: проведение олимпиад для вьетнамских школьников; поддержка преподавания и изучения русского языка как иностранного; развитие сотрудничества с университетами и школами Вьетнама, в т. ч. в которых преподается русский язык; работа со студентами и выпускниками университета из СРВ; участие в российско-вьетнамских межгосударственных программах подготовки кадров для СРВ. Вывод: все изучаемые университеты используют сочетание различных вышеперечисленных инструментов в комплексе, не сосредотачиваясь только на одном из них. Уникальные инструменты для рекрутинга вьетнамских студентов используются Дальневосточным федеральным университетом (представительство университета в СРВ, развитие вьетнамистики в университете, участие в деятельности Российско-Вьетнамского Тропического научно-исследовательского и технологического центра); Томским политехническим университетом целенаправленно ведется сотрудничество с вьетнамскими бизнес-компаниями. Особую модель представляет собой экспорт образовательных услуг МИФИ, в котором целевым образом ведется подготовка специалистов из Вьетнама в области атомной энергетики. Реализация этой модели обусловлена отраслевой спецификой университета.
\end{abstract}

Ключевые слова: Экспорт высшего образования, рекрутинг иностранных студентов, международная образовательная миграция, высшее образование, Вьетнам, интернационализация. 
Исследование лучших практик привлечения иностранных обучающихся в вузы Российской Федерации из Социалистической Республики Вьетнам было начато в 2018 г. Актуальность вопроса связана с ростом международной образовательной миграции, которая, по данным Института статистики ЮНЕСКО, уже к 2017 г. достигла 5,3 миллионов человек, обучающихся за рубежом по всему миру [1]. Значимость происходящих миграционных процессов связана не только с количественным ростом иностранных студентов в образовательных учреждениях, но и с политическим, экономическим и культурным значением происходящих изменений, а также с целенаправленной деятельностью национальных правительств и университетов по расширению экспорта высшего образования.

Конкуренция на международном рынке образования, связанная с появлением новых игроков, поощрением правительствами многих стран интернационализации образования, общемировой тенденцией на сокращение государственного финансирования университетов, а также с ростом возможностей населения в развивающихся странах получать образование за рубежом становится все сильнее. Тем важнее анализ наиболее эффективных мер, применяемых ведущими вузами с целью привлечения иностранных обучающихся из приоритетных стран.

Одной из наиболее перспективных стран в сфере экспорта образования является Социалистическая Республика Вьетнам, находящаяся на восходящем тренде исходящей академической мобильности: согласно данным Института ЮНЕСКО по статистике, число граждан Вьетнама, выезжающих с целью получения высшего образования за рубеж с 2013 по 2017 г., увеличилось на 69 \%, достигнув к 2017 г. 94662 чел. [1].

Россия входит в топ-10 стран-экспортеров высшего образования во Вьетнаме, перспективы экспорта для российских вузов оцениваются экспертами как высокие [2], при этом учитываются динамика роста ВВП во Вьетнаме на протяжении последних 25 лет, наличие значительной доли среднего класса, высокая доля молодого населения, а также развитое межправительственное сотрудничество России и Вьетнама, наличие поддержки мобильности на правительственном уровне и поддержка русского языка во Вьетнаме. Согласно оценке РАНХиГС рост студентов из Вьетнама может достичь цели в 5000 человек к 2024 г. при активизации механизмов привлечения иностранных студентов.

\section{Теоретические аспекты исследования механизмов рекрутинга}

Инструменты привлечения университетами иностранных студентов изучаются на протяжении достаточно длительного времени, и на сегодняшний день накоплен в целом большой объем исследований по данной тематике. Определение эффективности механизмов рекрутинга тесно связано с факторами, которые являются определяющими при выборе абитуриентами и их семьями высшего учебного заведения в другой стране.

Первые исследования, посвященные данной проблеме, были проведены в США и Австралии, система высшего образования в которых в значительной степени изначально была ориентирована на экспорт.

Так, Т. Маццарол и Г. Сутар [3] в 2002 г. на основе опроса 879 иностранных студентов, обучающихся в 10 австралийских колледжах и университетах, выделили восемь факторов, которые обеспечивают выбор зарубежного учебного заведения: 1) репутация университета; 2) признание вузом предыдущего образования; 3) репутация преподавательского состава; 4) наличие связей с другими известными абитуриенту университетами; 5) большое число иностранных студентов, обучающихся в университете; 6) наличие известных выпускников университета; 7) рекомендации друзей и родственников; 8) стоимость обучения и других расходов, связанных с пребыванием вне дома. 
В 2013 г. О. Озтургут [4] провел социологическое исследование среди вузов США с наибольшим числом обучающихся из зарубежных стран на предмет практик рекрутинга иностранных студентов. Им были выделены следующие инструменты экспорта образовательных услуг (в порядке частоты использования на уровне бакалавриата): 1) посещение и участие в международных образовательных выставках и рекрутинговых мероприятиях; 2) обеспечение академической поддержки и использование ресурсов кампуса; 3) работа с выпускниками-иностранцами; 4) пассивный маркетинг (наличие информационных материалов в Интернете); 5) работа с персоналом университета (обеспечение качественной работы офиса иностранных студентов, использование командировок профессорско-преподавательского состава для рекрутинга); 6) партнерство с другими организациями в стране рекрутинга; 7) работа с агентами; 8) «сарафанное радио». Автор также приводит примеры, когда встречи с руководством колледжей в стране рекрутинга, неакадемическими организациям и консультантами упоминаются в качестве инструментов экспорта вузом образовательных услуг.

В Турции в 2018 г. Э. Гёк и С. Гюмюс [5] по результатам опроса представителей 15 турецких университетов среди широко используемых инструментов рекрутинга выделили не только традиционные методы, как участие в выставках, найм агентов, онлайн-маркетинг и выездные тестирования, но пришли к выводу о важности работы с иностранными студентами как ресурсом для рекрутинга. В частности, университеты организуют их визиты в школы своей родной страны, проводят встречи с их семьями в ходе выездных мероприятий, используют их в качестве ассистентов в международных офисах вузов.

А в следующем году канадский исследователь Д.Д. Скотт (Университет Саскачевана) [6] сопоставил факторы, определившие поступление иностранных студентов в университет, с мерами, принимаемыми университетом для привлечения иностранных студентов. Автор по итогам исследования выделил следующие наиболее значимые факторы: 1) уровень профессорско-преподавательского состава; 2) наличие подходящих образовательных курсов и программ; 3) проведение международных конференций на базе университета; 4) финансовые факторы (стипендии, стоимость обучения, стоимость проживания); 5) репутация и место университета в рейтингах; 6) доступность и оперативность получения информации об университете.

Если говорить о России, то среди исследователей, занимающихся практиками привлечения иностранных студентов российскими вузами, можно выделить А.В. Меликян [7], которая провела анализ взаимосвязей между внутренними факторами, связанными с деятельностью российских университетов по привлечению иностранных обучающихся, и показателями результативности экспорта образовательных услуг этими университетами. Автором были отобраны следующие факторы, характеризующие деятельность вузов: 1) диверсификация образовательных программ; 2) реализация международных программ двух дипломов; 3) реализация программ транснационального образования; 4) сетевое партнерство с иностранными вузами; 5) стоимость образовательных услуг для иностранных учащихся; 6) коммерциализация обучения иностранных учащихся (доля иностранных студентов, обучающихся на коммерческой основе); 7) представленность информации о вузе в Интернете; 8) селективность вуза (предъявление высоких требований к уровню знаний и навыков абитуриентов). Проведенное исследование показало, что наиболее успешные вузы в сфере экспорта образовательных услуг реализуют наибольшее число программ двойных дипломов с зарубежными университетами и активно включены в международные сети и консорциумы вузов. 
Возросшее в последние годы внимание к экспорту образовательных услуг российскими университетами и определение его в качестве одного из приоритетов государственной политики в области образования обусловили появление ряда работ прикладного характера. Так, в коллективной монографии [8] в рамках проекта повышения конкурентоспособности ведущих российских университетов среди ведущих мировых научно-образовательных центров (Проект 5-100) представлен обзор развития системы привлечения иностранных студентов в российском университете. Авторы работы выделяют три основные группы рекрутинговых мероприятий. К первой из них относятся академические мероприятия или формирование портфеля образовательных программ: образовательные программы и курсы на английском языке, совместные образовательные программы с зарубежными вузами-партнерами, программы параллельных степеней, совместные академические программы с ведущими национальными вузами и научно-образовательными центрами, программы международной академической мобильности, программы довузовской подготовки иностранных студентов, международная аккредитация образовательных программ. Вторая группа - маркетинговые мероприятия: event-маркетинг (специализированные мероприятия по продвижению образовательных услуг), подготовка рекламно-информационных и презентационных материалов об образовательных услугах и продуктах университета, веб- и медиамаркетинг. В третью группу выделены мероприятия по исследованию предпочтений и ориентаций целевых групп иностранных студентов. Отдельный блок работы по привлечению иностранных студентов, по мнению авторов, составляет взаимодействие университета с внешними агентами: родителями (семьями) иностранных абитуриентов, иностранными выпускниками вуза, зарубежными университетами, зарубежными образовательными учреждениями общего и среднего образования, рекрутинговыми агентствами, национальными организациями - операторами образовательных услуг, государственными учреждениями и органами власти, средствами массовой информации.

Масштабная экспертная работа была проведена в рамках реализации приоритетного проекта «Развитие экспортного потенциала Российской системы образования» сотрудниками Центра компетенций международных служб образовательных организаций Российской академии народного хозяйства и государственной службы при Президенте РФ (РАНХиГС) [9]. В ходе реализации проекта были проведены маркетинговые исследования международного образовательного рынка и разработаны маркетинговые рекомендаций российским образовательным организациям по продвижению образовательных программ на международном образовательном рынке. Данное исследование было выполнено по 10 странам экспорта российского образования, куда вошла Социалистическая Республика Вьетнам. Анализ был выполнен по следующим блокам: общая характеристика страны; экономика страны; система образования страны; обучение в зарубежных странах; встроенность в мировое образовательное пространство.

На основе данного анализа экспертами РАНХиГС была проработана стратегия увеличения доли России на международном рынке высшего образования. Социалистическая Республика Вьетнам была отнесена к третьей группе стран - с высоким потенциалом увеличения числа студентов. На основе анализа зарубежного опыта экспертами были даны рекомендации для вузов по привлечению студентов из Вьетнама, которые включали в себя: открытие кампусов университетов на территории Вьетнама, открытие офисов и представительств России как экспортера высшего образования на территории Вьетнама, развитие совместных образовательных программ, реализацию онлайн- и смешанного образования, выстраивание системной работы по рекрутингу во Вьетнаме с привлечением рекрутинговых агентов и др. 
Несмотря на изученность общих вопросов образовательной миграции из СРВ в Россию [10-14], нами не были обнаружены работы, в которых изучались особенности привлечения иностранных обучающихся из Социалистической Республики Вьетнам. Единственным исключением стала указанная выше работа экспертов РАНХиГС, однако в ней не описаны инструменты, которые уже используют российские вузы для развития экспорта образовательных услуг в Социалистической Республике Вьетнам.

В целом изучение предшествующих исследований показало, что в основном авторы обращают внимание на инструментарный фактор рекрутинговой деятельности и в недостаточной мере принимают во внимание специфику стран, поэтому практически отсутствуют исследования, учитывающие региональную, страновую специфику экспорта образовательных услуг во Вьетнам.

Целью работы является выявление успешных практик экспорта образовательных услуг российских вузов в СРВ.

\section{Методология}

Методология исследования основывалась на выявлении и обобщении практик российских университетов, которые целевым образом направлены на привлечение абитуриентов из СРВ (т. е. не предполагают в качестве результата рекрутинга абитуриентов из других стран). Были рассмотрены академические мероприятия (формирование портфеля образовательных программ), маркетинговые мероприятия и различные форматы взаимодействий со студентами и выпускниками, а также внешними агентами, включая вьетнамские и российские организации, работающие в СРВ.

Проведенный анализ статистических данных Центра социологических исследования Минобрнауки России, Института статистики ЮНЕСКО, анализ открытых источников в сети Интернет, а также включенное наблюдение, которое применялось в рамках профессиональной деятельности в Управлении международного сотрудничества Северного (Арктического) федерального университета (выездные мероприятия во Вьетнам ноябрь 2018 г., февраль 2019 г., октябрь 2019 г.; участие в образовательном проекте «Вузы России», международной образовательной выставке; взаимодействие с образовательными учреждениями), позволили выявить эффективные существующие практики российских университетов по привлечению вьетнамских граждан на обучение.

Для анализа были отобраны университеты с наибольшим числом студентов из Вьетнама: Российский университет дружбы народов (217 человек) [9], Национальный исследовательский ядерный университет МИФИ (151 человек) [15], Национальный исследовательский Томский политехнический университет $(160$ человек) $[9,16]$, СанктПетербургский государственный политехнический университет (185 человек) [9], Тульский государственный университет (90 человек) [17], а также университеты, которые начали работать над увеличением числа обучающихся из СРВ сравнительно недавно, но активно и успешно (Дальневосточный федеральный университет - 84 человека [18], Томский государственный университет - более 50 человек [19]). Дополнительным фактором отбора вышеперечисленных университетов стало то, что на их сайтах встречается наибольший объем релевантной для настоящего исследования информации.

Ограничением данного исследования является то, что не все практики по привлечению абитуриентов из СРВ могли быть отражены публичном информационном пространстве. В частности могла быть не отражена работа с рекрутинговыми агентами, представляющими интересы университета в стране. Вместе с тем на веб-сайтах всех исследуемых университетов удалось обнаружить значительное количество новостных материалов, посвященных работе во Вьетнаме, а также взаимодействию с вьетнамски- 
ми студентами внутри вуза, что позволяет говорить о существенном внимании, которое уделяется данному направлению со стороны руководства университетов.

Еще одним ограничением является преувеличение успехов на вьетнамском «направлении» в официальных информационных ресурсах университета. Вместе с тем автор не ставит своей задачей в рамках настоящей работы проводить оценку инструментов рекрутинга, а сосредотачивается лишь на их констатации.

На дальнейших этапах исследования планируется проведение экспертного опроса коллег из российских вузов, реализующих экспорт российских образовательных программ во Вьетнам, что позволит получить более глубокую картину экспортного потенциала российского образования во Вьетнаме и факторов формирования образовательной миграции.

\section{Результаты}

Проведенный анализ позволил выявить практики привлечения абитуриентов из Социалистической Республики Вьетнам, которые используют исследуемые российские университеты, а также установить распространенность использования этих практик (см. краткую сводку в приложении).

\section{Олимпиады для вьетнамских школьников}

Наиболее распространённым инструментом привлечения студентов из Вьетнама является участие вузов в проведении олимпиад для старшеклассников, реализуемых Представительством Россотрудничества во Вьетнаме (Российский центр науки и культуры в Ханое) в рамках отбора на квоту Правительства Российской Федерации (бесплатное обучение для вьетнамских студентов). Так, в 2019 г. в олимпиадах приняли участие представители 16 университетов РФ [20], в том числе ДВФУ, ТГУ, ТПУ, ТулГУ, САФУ [21]. Данная олимпиада проводится параллельно с образовательным проектом «Вузы России» [22], где РЦНК в Ханое выступает площадкой для проведения мероприятий в области образования, установления контактов между образовательными и научными организациями, профильными ведомствами, а также активно содействует продвижению российских вузов и популяризации российского образования во Вьетнаме, расширения научно-образовательного и гуманитарного сотрудничества России и Вьетнама.

В 2020 г. из-за эпидемиологической ситуации олимпиада по русскому языку в рамках отбора на квоту Правительства Российской Федерации прошла в дистанционном формате на онлайн-платформе Томского государственного университета.

Дальневосточный федеральный университет регулярно проводит олимпиаду «Океан знаний». Олимпиада 2019 г. по математике собрала около 50 школьников [23]. В 2017 г. ДВФУ провел олимпиаду по русскому языку, математике и физике в четырех крупнейших городах страны, охватив более 640 человек [24, 25].

В разные годы олимпиады для вьетнамских школьников проводил Российский университет дружбы народов [26, 27].

\section{Продвижение русского языка}

Еще одним инструментом, обеспечивающим присутствие на образовательном рынке Вьетнама, является поддержка русского языка как иностранного (РКИ), включая поддержку преподавателей и обучающихся, а также тестирования РКИ.

Так, Российский университет дружбы народов в рамках программы «Время учиться в России - время учить русский» проводит повышение квалификации вьетнамских преподавателей и учителей русского языка, оказывает методическую помощь образовательным учреждениям, в которых осуществляется преподавание русского языка, 
а также проводит открытые уроки и страноведческие викторины для школьников и студентов [28]. Подобные мероприятия проводятся в том числе в сотрудничестве с Тюменским государственным университетом [29]. Сотрудники РУДН также принимают участие в организации дней русского языка во Вьетнаме [30].

В 2018 г. Томский государственный университет и Хошиминский педагогический университет заключили договор на открытие локального центра тестирования по русскому языку как иностранному [31].

Сотрудники Санкт-Петербургского политехнического университета проводили лекции для вьетнамских преподавателей русского языка, организовали экспресс-курсы русского языка, концертную программу, презентацию культуры, в т. ч. русской кухни, викторины в рамках Фестиваля русского языка и культуры в Хошимине и на Неделе русского языка в Ханое в 2018 г. [32].

\section{Сотрудничество со школами СРВ}

Томские университеты, прежде всего ТГУ, развивают такое направление, как прямое сотрудничество с вьетнамскими школами [33]. Томский госуниверситет ведет наиболее интенсивное сотрудничество со Старшей спецшколой им. Чан Фу в Хайфоне. Для старшеклассников ежегодно организуется летняя школа, включающая в себя интенсивную подготовку по русскому языку, знакомство с университетом, Томском и его окрестностями [34]. В декабре 2019 года специалисты Томского государственного университета посетили Вьетнам для проведения стратегических сессий с педагогами и администраторами и проектных интенсивов со школьниками в рамках проекта «Развитие цифровой грамотности школьников и подготовка педагогических команд для цифровой трансформации образования» [35].

Томский политехнический университет совместно с ханойским филиалом Государственного института русского языка им. А.С. Пушкина проводят для вьетнамских школьников уроки русского языка в дистанционном формате [36].

Уже сейчас можно говорить об успехе практики сотрудничества с вьетнамскими школами, по крайней мере в ТГУ: в 2019 г. в университете проходили обучение около 20 выпускников школы Чан Фу в Хайфоне [37].

\section{Развитие межуниверситетского сотрудничества}

Одни из наиболее тесных межуниверситетских связей с СРВ развивает СанктПетербургский политехнический университет. Совместно с Университетом Бинь Зыонг (БЗУ) реализуется широкомасштабное сотрудничество, включающее в себя реализацию совместных образовательных программ с интенсивным изучением русского языка, создание лабораторий и научных центров, участие в конференциях. В 2018 г. в рамках Дней российской культуры и науки во Вьетнаме была открыта совместная лаборатория СПбПУ и БЗУ «Микропроцессорная техника» по направлению «Разработка цифровых устройств на FPGA» [38]. СПбПУ совместно с Институтом электроники, информатики и автоматики (VIELINA) реализовал проект, посвященный телекоммуникационным системам сбора и обработки информации, результатами которого стали совместные публикации, совместное руководство аспирантом, а также программа повышения квалификации «Тепловая электрическая станция» [39]. Политехнический университет также реализует сотрудничество в области телекоммуникаций и оптической диагностики с Ханойским университетом электроники, информатики и автоматики [40] и участвует в совместных конкурсах научных исследований с Ханойским университетом науки и технологий [41]. 
В рамках сотрудничества с Томским госуниверситетом два-три сотрудника Хайфонского университета ежегодно проходят обучение в аспирантуре и магистратуре ТГУ [42]. На филологическом факультете ТГУ обучаются студенты и аспиранты из Ханойского университета [43].

Важным партнером Дальневосточного федерального университета является Ханойский государственный университет (ХГУ), на базе которого действует представительство ДВФУ [44]. Тесное сотрудничество ведется между вьетнамским отделением ДВФУ и факультетом русского языка и культуры Университета иностранных языков ХГУ.

Томский политехнический университет в составе консорциума российских, вьетнамских и европейских вузов участвует в реализации проекта «Разработка образовательной программы в области интеллектуальных энергетических систем в российских и вьетнамских вузах» в рамках программы Европейского союза Erasmus+ [45].

Важным направлением межвузовского сотрудничества является академическая мобильность. Студенты ДВФУ, изучающие вьетнамский язык, ежегодно проходят десятимесячную стажировку в Ханойском государственном университете [46]. Дальневосточный университет проводит конкурс на базе ХГУ для вьетнамских студентов, победители которого получают право на бесплатное участие в Международной летней школе ДВФУ. Студенты Университета технологий и образования (Хошимин) проходили в СПбПУ обучение по программам бакалавриата и магистратуры [40].

\section{Работа со студентами и выпускниками из Вьетнама}

Взаимодействие со студентами из Вьетнама важно не только с точки зрения создания комфортных условий для студентов, возможностей для их самореализации и знакомства принимающего сообщества с их культурой. Исследования показывают значимую роль мнения студентов, обучающихся или обучавшихся в вузе, на выбор абитуриентами. Большое число мероприятий, посвященных вьетнамской культуре проводится на базе Российского университета дружбы народов: ежегодная Неделя вьетнамской культуры [47], конкурс «Мисс Вьетнам» [48]. Фестиваль вьетнамской культуры проходит в Тульском государственном университете [49]. В Томском политехническом университете ежегодно проводится День Вьетнама - «большой праздник национальных песен, танцев, игр и кухни» [50]. В Дальневосточном федеральном университете в 2016 г. с участием Генерального консула Вьетнама во Владивостоке прошла выставка «Традиционная культура Вьетнама», посвященная 45-летию Приморского общества дружбы с Вьетнамом [51]. Администрация СПбПУ помогает вьетнамским студентам отмечать День независимости Республики Вьетнам [52].

Российский центр науки и культуры в Ханое с 2016 г. реализует проект Единый день выпускника (ЕДВ), направленный на активизацию диалога российской стороны с вьетнамскими государственными, научными и общественными деятелями, закончившими советские и российские университеты [53]. Встречи с вьетнамскими выпускниками организует Российский университет дружбы народов [54]. Филиал Ассоциации выпускников ТПУ действует в Ханойском техническом университете [55].

\section{Целевая подготовка кадров в рамках межгосударственного сотрудничества}

Значимое место в российско-вьетнамских отношениях занимает сотрудничество в области атомной энергетики, в том числе подготовка кадров для атомной отрасли СРВ. Данное направление является ключевым и фактически единственным инструментом экспорта образовательных услуг для Национального исследовательского ядерного уни- 
верситета МИФИ, где подготовка иностранных специалистов ведется на базе Обнинского института атомной энергетики [56]. Вклад МИФИ был отмечен на самом высоком уровне: в 2018 г. университет был награжден Орденом Дружбы Социалистической Республики Вьетнам за вклад в подготовку высококвалифицированных специалистов для атомной отрасли Вьетнама [57]. Также целевой подготовкой кадров для атомной отрасли СРВ занимаются Дальневосточный федеральный и Томский политехнический университеты. В 2015-2016 гг. Вьетнам направил в эти вузы 60 и 20 студентов соответственно [58].

Обучение вьетнамских студентов в российских университетах ведется также в рамках межгосударственной программы «долг - помощь» [49]. Большая часть вьетнамских студентов Тульского государственного университета учится в рамках этой программы по специальности «Лечебное дело».

\section{Уникальные инструменты привлечения студентов из СРВ}

Наряду с распространенными практиками рекрутинга были обнаружены механизмы, характерные только для одного из рассматриваемых университетов.

Важным конкурентным преимуществом Дальневосточного федерального университета является наличие единственного среди всех российских вузов представительства во Вьетнаме [59]. Представительство было открыто в 2018 г. в Ханойском государственном университете (ХГУ). На его базе ДВФУ проводит профориентационные и презентационные мероприятия, а также преподавание русского языка среди школьников и студентов СРВ [60]. Кроме того, на базе представительства проводятся мероприятия по продвижению культуры России во Вьетнаме: так, в 2019 г. при поддержке фонда «Русский мир» и Общества вьетнамско-российской дружбы, был организован фестиваль «Русские мелодии в сердце Ханоя», приуроченный к 25-летию подписания Договора об основах дружеских отношений между Россией и Вьетнамом [61].

Уникальное положение ДВФУ также обеспечивается благодаря развитой школе вьетнамистики, действующей с конца 1980-х гг. Университет является лидером в РФ по числу студентов, изучающих вьетнамский язык; в ДВФУ проводятся олимпиады [62] и профильные образовательные мероприятия (например, модель переговорного процесса по формату Комиссии по реке Меконг для студентов ДВФУ) [63].

Дальневосточный федеральный университет в 2019 г. был включен в состав Координационного комитета совместного Российско-Вьетнамского Тропического научноисследовательского и технологического центра (Тропический центр) [64]. Тропический центр представляет собой уникальную междисциплинарную многопрофильную научную организацию, которая действует в рамках стратегического партнерства России и Вьетнама в области науки, технологий и военно-технического сотрудничества. Центр осуществляет свою деятельность в областях тропического материаловедения, тропической экологии и тропической медицины. Примечательно, что ДВФУ - единственный из изучаемых университетов - член Координационного комитета центра [65]. С точки зрения экспорта образовательных услуг участие в деятельности Тропического центра предоставляет возможность развития межвузовского сотрудничества, а также преподавания русского языка для вьетнамских сотрудников центра.

Томский политехнический университет как один из центров научных разработок укрепляет присутствие в СРВ посредством сотрудничества с вьетнамскими компаниями, которые регулярно посещают университет [66-68]. 


\section{Заключение}

Анализ опыта наиболее успешных российских вузов на вьетнамском рынке образования показывает, что российские вузы с наибольшим числом студентов из СРВ или с наибольшим приростом студентов используют сочетание различных практик, диверсифицируя инструменты рекрутинга и развивая широкое научно-образовательное сотрудничество с Вьетнамом. В ходе исследования были выявлены следующие практики, способствующие набору вьетнамских студентов: 1) проведение олимпиад для вьетнамских школьников; 2) поддержка преподавания и изучения русского языка как иностранному; 3) развитие сотрудничества со школами Вьетнама, в которых преподается русский язык; 4) развитие сотрудничества с университетами Вьетнама; 5) работа со студентами и выпускниками университета из СРВ; 6) участие в российско-вьетнамских межгосударственных программах подготовки кадров для СРВ. Все изучаемые университеты используют сочетание различных вышеперечисленных инструментов в комплексе, не сосредотачиваясь только на одном из них. Уникальные инструменты для рекрутинга вьетнамских студентов используются Дальневосточным федеральным университетом (представительство университета в СРВ, развитие вьетнамистики в университете, участие в деятельности Российско-Вьетнамского Тропического научноисследовательского и технологического центра) и Томским политехническим университетом (сотрудничество с вьетнамскими компаниями). Особую модель представляет собой экспорт образовательных услуг МИФИ, в котором целевым образом ведется подготовка специалистов из Вьетнама в области атомной энергетики. Реализация этой модели обусловлена отраслевой спецификой университета.

Таким образом, для успешного развития экспорта образовательных программ во Вьетнам российским вузам видится необходимым сочетание различных форм и форматов взаимодействия непосредственно с абитуриентами (выставки, олимпиады) с развитием сотрудничества с внешними агентами, начиная от студентов и выпускников из Вьетнама, заканчивая научно-образовательным сотрудничеством со школами и вузами $\mathrm{CPB}$, партнерством с вьетнамскими компаниями, а также возможность уделить особое внимания поддержке русского языка и участию в российско-вьетнамских межгосударственных программах подготовки кадров для СРВ. Сочетание различных форматов взаимодействия наряду со специализацией и востребованностью программ самого вуза во Вьетнаме, а также выстраиванием долговременных и надежных партнерских отношений может привести к успеху в развитии гуманитарного сотрудничества и экспорта образования.

Также необходимо отметить, что анализ предшествующих исследований и опыта российских университетов показал, что вузы РФ применяют различные инструменты рекрутинга преимущественно из традиционного спектра, за исключением томских университетов, ДВФУ, внедряющих дополнительные практики, в то время как видится необходимым помимо традиционных инструментов использовать форматы, учитывающие этнокультурную специфику региона. Несмотря на сравнительно высокую изученность механизмов рекрутинга иностранных студентов, практически отсутствуют научные работы, фокусирующиеся на данной региональной, страновой специфике, и этот вопрос, на наш взгляд, может стать предметом дальнейшего исследования. 
Приложение

\author{
Использование практик привлечения абитуриентов \\ из Социалистической Республики Вьетнам российскими университетами \\ Practices of attracting students from the Socialist Republic \\ of Vietnam by Russian universities
}

\begin{tabular}{|c|c|c|c|c|c|c|c|}
\hline $\begin{array}{l}\text { Университет } \\
\text { University }\end{array}$ & 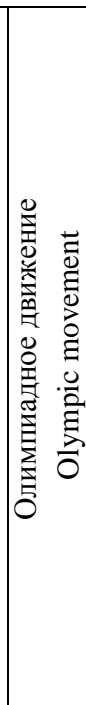 & 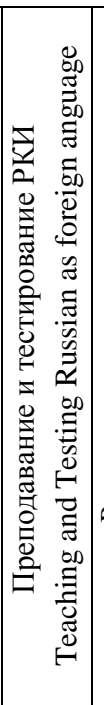 & 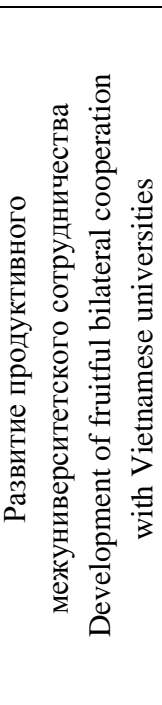 & 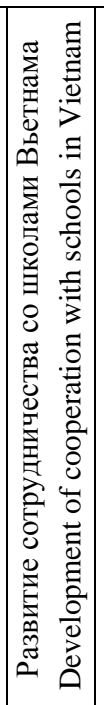 & 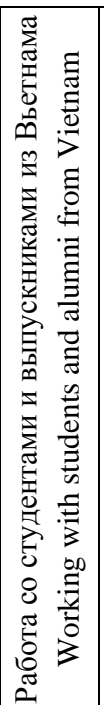 & 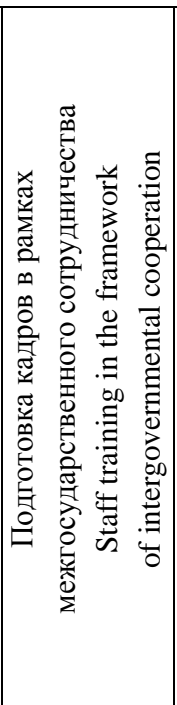 & $\begin{array}{c}\text { Уникальные } \\
\text { (не встречающиеся у других вузов) } \\
\text { практики } \\
\text { Unique } \\
\text { (not found in other universities) } \\
\text { practices }\end{array}$ \\
\hline ДВФУ/FEFU & + & + & + & - & + & + & $\begin{array}{l}\text { - Представительство ДВФУ во Вьетнаме/ } \\
\text { Representative office of FEFU in Vietnam; } \\
\text { - вьетнамистика/Vietnamese Studies; } \\
\text { - участие в деятельности Российско- } \\
\text { Вьетнамского Тропического научно-иссле- } \\
\text { довательского и технологического центра/ } \\
\text { Participation in the activities of the Russian- } \\
\text { Vietnamese Tropical Research and Technology } \\
\text { Center }\end{array}$ \\
\hline ТГУ/ТSU & + & + & + & + & - & - & - \\
\hline ТПУ/ТРU & + & + & + & + & + & + & $\begin{array}{l}\text { Развитие сотрудничества с вьетнамскими ком- } \\
\text { паниями } \\
\text { Development of cooperation with Vietnamese } \\
\text { business companies }\end{array}$ \\
\hline $\begin{array}{l}\text { РУДН } \\
\text { RUDN University }\end{array}$ & + & + & - & - & + & - & - \\
\hline МИФИ/МЕРНІ & - & + & - & - & - & + & - \\
\hline СПбПУ/SPbPU & - & + & + & $\begin{array}{lll}- & & \\
-\end{array}$ & + & - & - \\
\hline ТулГУ/TulSU & + & + & - & - & + & + & - \\
\hline
\end{tabular}

\title{
СПИСОК ЛИТЕРАТУРЫ
}

1. Education: Outbound internationally mobile students by host region. // UNESCO Institute of Statistics. URL: http://data.uis.unesco.org/ (дата обращения 03.09.2020).

2. Стратегия увеличения доли России на международном рынке высшего образования // РАНХИГС. URL: https://www.ranepa.ru/images/docs/nayka/strategy.pdf (дата обращения 04.09.2020).

3. Mazzarol T., Soutar G. «Push-pull» factors influencing international student destination choice // International Journal of Education Management. - 2002. - № 16 (2). - P. 82-90.

4. Özturgut O. Best Practices in recruiting and retaining international students in the U.S. // Current Issues in Education. - 2013. - № 16 (2). URL: http://cie.asu.edu/ojs/index.php/cieatasu/article/view/1213 (дата обращения 04.09.2020). 
5. Gok E., Gumus S. International student recruitment efforts of Turkish universities: rationales and strategies // Annual review of comparative and international education / Ed. by A.W. Wiseman. - Betnthelem Bingley, UK: Emerald.,, 2018. - P. 231-256.

6. Scott J.J. International student mobility: International student recruitment at the University of Saskatchewan // A Thesis Submitted to the College of Graduate and Postdoctoral Studies in Partial Fulfillment of the Requirements For the Degree of Master of Education in the Department of Educational Administration University of Saskatchewan. - Saskatoon, 2019. URL: https://harvest.usask.ca/bitstream/handle/ 10388/12554/SCOTT-THESIS-2020.pdf?sequence=1\&isAllowed=y (дата обращения 05.09.2020).

7. Меликян А.В. Внутренние факторы результативности экспорта образования в российских вузах // Вопросы образования. - 2018. - № 3. - C. 146-179. URL: https://cyberleninka.ru/article/n/vnutrenniefaktory-rezultativnosti-eksporta-obrazovaniya-v-rossiyskih-vuzah (дата обращения 11.09.2020).

8. Привлечение иностранных студентов в российские университеты. Практическое руководство: монография / Е.В. Вашурина, О.А. Вершинина, Ч.Ф. Газиева и др. - Екатеринбург: Уральский федеральный университет: ЭБС АСВ, 2016. - 234 с.

9. Отчет о выполнении работ по Контрольной точке № 45 І-этап маркетинговых исследований международного образовательного рынка, в том числе разработка маркетинговых рекомендаций российским образовательным организациям по продвижению образовательных программ на международном образовательном рынке // РАНХИГС. URL: https://www.ranepa.ru/images/docs/nayka/otchet-KT45.pdf (дата обращения 11.09.2020).

10. Рязанцев С.В., Письменная Е.Е. Миграционные планы вьетнамской молодежи в контексте Российской политики привлечения образовательных мигрантов // Вьетнамские исследования. - 2017. № 7. - С. 204-211.

11. Рязанцев С.В., Письменная Е.Е. Образовательная и трудовая миграция вьетнамцев в Россию: тенденции и потенциал // Вьетнамские исследования. - 2013. - № 3. - С. 65-74.

12. Миграция населения из Вьетнама: современные особенности и возможности для России / С.В. Рязанцев, Р.В. Маныиин, Е.М. Моисеева, В.Н. Пинчук // Вьетнамские исследования. - 2019. - № 2. C. $29-43$.

13. Соколов А.А. Современная образовательная миграция из Вьетнама: возможности и вызовы // ЮВА: актуальные проблемы развития. - 2017. - № 35. - С. 184-205.

14. Динь Тхи Тху Хуен. История становления и развития обучения русскому языку во Вьетнаме // Педагогика. Психология. Философия. - 2019. - № 3 (15). - С. 5-13.

15. Международное сотрудничество // Национальный исследовательский ядерный университет «МИФИ» (НИЯУ МИФИ). Обнинский институт атомной энергетики (ИАТЭ). URL: http://www. iate.obninsk.ru/node/73 (дата обращения 05.09.2020).

16. Специалистов для ведущей нефтегазодобывающей компании Вьетнама планируют готовить в Томском политехе // Национальный исследовательский Томский политехнический университет. URL: https://news.tpu.ru/news/2016/08/05/25664/ (дата обращения 11.09.2020).

17. Вьетнамский гала-фест // Тульский государственный университет. URL: http://tsu.tula.ru/news/all/9433 (дата обращения 11.09.2020).

18. В ДВФУ вдвое увеличилось число студентов из Вьетнама // Дальневосточный федеральный университет. URL: https://www.dvfu.ru/news/fefu-news/at_the_university_has_doubled_the_number_of_ students_from_vietnam/?sphrase_id=1374225 (дата обращения 11.09.2020).

19. Сибирский гринфилд. Проректор ТГУ Артем Рыкун о 800 иностранных студентах и миграционном цунами // Томский обзор. URL: https://obzor.city/article/617749---sibirskij-grinfild.-prorektor-tgu-artemrykun-o-800-inostrannyh-studentah-i-migracionnom-cunami (дата обращения 11.09.2020).

20. ТГУ участвует в образовательных проектах во Вьетнаме // Национальный исследовательский Томский государственный университет. URL: http://www.tsu.ru/podrobnosti/tgu-uchastvuet-vobrazovatelnykh-proektakh-vo-vetname/?sphrase_id=248958 (дата обрашения 11.09.2020).

21. 11-й этап долгосрочного образовательного проекта «Вузы России» во Вьетнаме // Российский центр науки и культуры в Ханое. URL: http://vnm.rs.gov.ru/ru/news/42854 (дата обращения 12.09.2020).

22. Долгосрочный образовательный проект «Вузы России» // Российский центр науки и культуры в Ханоe. URL: http://vnm.rs.gov.ru/ru/activities/180/projects/242 (дата обращения 05.09.2020).

23. ДВФУ провел олимпиаду по математике для школьников во Вьетнаме // Дальневосточный федеральный университет. URL: https://www.dvfu.ru/news/admission/the_university_held_a_mathematics_ contest_for_students_in_vietnam/ (дата обращения 11.09.2020).

24. Предметные олимпиады помогут вьетнамским школьникам поступить в ДВФУ // Дальневосточный федеральный университет. URL: https://www.dvfu.ru/news/international_cooperation/olympiad_will_ help_vietnamese_students_to_enroll_at_fefu/ (дата обращения 11.09.2020). 
25. Школьники Вьетнама попробовали свои силы в олимпиаде «Океан знаний» ДВФУ // Дальневосточный федеральный университет. URL: https://www.dvfu.ru/news/international_cooperation/students_ of_vietnam_have_tried_their_hand_at_the_olympics_far_eastern_federal_university/ (дата обращения 11.09.2020).

26. РУДН участвует в олимпиадном движении во Вьетнаме // Российский университет дружбы народов. URL: http://www.rudn.ru/media/news/about_rudn/rudn-uchastvuet-v-olimpiadnom-dvijenii-vo-vetname (дата обращения 11.09.2020).

27. В Ханое состоялась Олимпиада РУДН по русскому языку. О рабочем визите делегации Университета во Вьетнам // Российский центр науки и культуры в Ханое. URL: http://old.rudn.ru/index.php? pagec=6190 (дата обращения 12.09.2020).

28. Визит делегации Российского университета дружбы народов в рамках Декабрьской методической недели в г. Ханое // Российский центр науки и культуры в Ханое. URL: http://vnm.rs.gov.ru/ \%20\%20/news/39642 (дата обращения 11.09.2020).

29. ТюмГУ готовит к поступлению вьетнамских абитуриентов // Тюменский государственный университет. URL: https://news.utmn.ru/news/mezhdunarodnaya-deyatelnost/641621/ (дата обращения 11.09.2020).

30. Командировка во Вьетнам // Филологический факультет РУДН. URL: http://phil.rudn.ru/vietnam_aprel (дата обращения 11.09.2020).

31. ТГУ - главный вуз по тестированию на знание русского языка в Хошимине // Национальный исследовательский Томский государственный университет. URL: http://www.tsu.ru/news/tgu-glavnyy-vuzpo-testirovaniyu-na-znanie-russkog/ (дата обращения 12.09.2020).

32. Русисты Политеха: популярность русского языка во Вьетнаме растет // Санкт-Петербургский политехнический университет Петра Великого (СПбПУ). URL: https://www.spbstu.ru/media/news/ international_activities/rusite-polytech-popularity-russian-language-vietnam-growing/ (дата обращения 11.09.2020).

33. ТГУ развивает сотрудничество со школами Вьетнама // Центр сопровождения иностранных студентов ТГУ. URL: http://studentcenter.tsu.ru/news/тгу-развивает-сотрудничество-со-школами-вьетнама (дата обращения 11.09.2020).

34. Старшеклассники из Вьетнама прошли интенсив по русскому языку в ТГУ // Национальный исследовательский Томский государственный университет. URL: http://www.tsu.ru/news/starsheklassniki-izvetnama-proshli-intensiv-po-ru/ (дата обращения 11.09.2020).

35. Команда ТГУ и школа Хайфона вместе сделали шаг к цифровому образованию // Национальный исследовательский Томский государственный университет. URL: http://www.tsu.ru/news/komanda-tgu-ishkola-khayfona-vmeste-sdelali-shag-/?nv=on (дата обращения 11.09.2020).

36. Преподаватели ТПУ начали онлайн-занятия по русскому языку для школьников из Вьетнама // Национальный исследовательский Томский политехнический университет. URL: https://news.tpu.ru/ news/2017/05/05/27150/ (дата обращения 11.09.2020).

37. ТГУ участвует в образовательных проектах во Вьетнаме // Национальный исследовательский Томский государственный университет. URL: http://www.tsu.ru/podrobnosti/tgu-uchastvuet-vobrazovatelnykh-proektakh-vo-vetname/ (дата обращения 11.09.2020).

38. Дни российской культуры и науки в университете Бинь Зыонг во Вьетнаме // Санкт-Петербургский политехнический университет Петра Великого (СПбПУ). URL: https://www.spbstu.ru/ media/news/international_activities/days-russian-culture-science-binh-zyong-university-vietnam/ (дата обращения 11.09.2020).

39. Политех продолжает научно-техническое партнерство с вузами Вьетнама // Санкт-Петербургский политехнический университет Петра Великого (СПбПУ). URL: https://www.spbstu.ru/media/ news/international_activities/prospects-joint-science-education-center-basis-vielina/ (дата обращения 11.09.2020).

40. Санкт-Петербург и Вьетнам: итоги сотрудничества и планы на будущее // Санкт-Петербургский политехнический университет Петра Великого (СПбПУ). URL: https://www.spbstu.ru/media/ news/international_activities/st-petersburg-vietnam-outcomes-of-cooperation-and-future-plans/(дата обращения 11.09.2020).

41. Делегация СПбПУ посетила Социалистическую Республику Вьетнам // Санкт-Петербургский политехнический университет Петра Великого (СПбПУ). URL: https://www.spbstu.ru/media/news/ international_activities/delegation-spbpu-socialist-republic-vietnam/ (дата обращения 11.09.2020).

42. Преподаватели Вьетнама будут учиться в аспирантуре и магистратуре ТГУ // Национальный исследовательский Томский государственный университет. URL: http://www.tsu.ru/news/prepodavatelivetnama-budut-uchitsya-v-aspiranture/ (дата обращения 11.09.2020). 
43. ТГУ развивает сотрудничество с ведущими вузами Вьетнама и Лаоса // Национальный исследовательский Томский государственный университет. URL: http://www.tsu.ru/news/tgu-razvivaetsotrudnichestvo-s-vedushchimi-vuzami/ (дата обращения 11.09.2020).

44. Образовательные программы ДВФУ представили во Вьетнаме // Дальневосточный федеральный университет. URL: https://www.dvfu.ru/news/international_cooperation/the_educational_program_of_ the_university_introduced_in_vietnam/ (дата обращения 11.09.2020).

45. Российские, вьетнамские и европейские вузы будут вместе готовить специалистов для «умной» энергетики // Национальный исследовательский Томский политехнический университет. URL: https://news.tpu.ru/news/2017/09/06/27602/ (дата обращения 11.09.2020).

46. Сотрудники ВИ-ШРМИ приняли участие в мероприятиях во Вьетнаме, посвященных 100-летию Октябрьской революции в России // Дальневосточный федеральный университет. URL: https://www. dvfu.ru/schools/school_of_regional_and_international_studies/news/the_staff_of_vi_srmi_took_part_in_eve nts_in_vietnam_dedicated_to_the_100th_anniversary_of_the_october_revolution_in_russia_/ (дата обращения 12.09.2020).

47. Вьетнамские студенты в России популяризируют отечественную культуру. URL: http://huunghivietnga.com.vn/news/vshcdpkajoizd-oprgdkpsh-v-nloozz-mlmryiyanzzhznryuplpdfdopvdkkryu-iryishcprnr (дата обращения 12.09.2020).

48. Конкурс «МИСС ВЬЕТНАМ» // Российский университет Дружбы народов. URL: http://www.rudn.ru/ media/news/about_rudn/konkurs-miss-vetnam (дата обращения 12.09.2020).

49. Вьетнамский гала-фест // Тульский государственный университет. URL: http://tsu.tula.ru/news/all/9433 (дата обращения 12.09.2020).

50. Традиционными сладостями, песнями и «танцем с бамбуком» в ТПУ отпразднуют День Вьетнама // Национальный исследовательский Томский политехнический университет. URL: https://news.tpu.ru/ news/2017/11/03/27877/ (дата обращения 12.09.2020).

51. Выставка в ДВФУ открыла месячник российско-вьетнамской дружбы в Приморье // Дальневосточный федеральный университет. URL: https://www.dvfu.ru/news/international_cooperation/ exhibition_the_university_opened_the_month_of_russian_vietnamese_friendship_in_primorye/ (дата обращения 12.09.2020).

52. Студенты отметили День Независимости Вьетнама // Санкт-Петербургский политехнический университет Петра Великого (СПбПУ). URL: https://www.spbstu.ru/media/news/international_ activities/students-celebrated-independence-day-vietnam/?sphrase_id=1407867 (дата обращения 12.09.2020).

53. Единый день выпускника во Вьетнаме Вьетнаме // Российский центр науки и культуры в Ханое. URL: http://vnm.rs.gov.ru/\%C2\%A0/news/58130 (дата обращения 12.09.2020).

54. Визит делегации РУДН в Таиланд и Вьетнам // Российский университет дружбы народов. URL: http://www.rudn.ru/media/news/about_rudn/vizit-delegacii-rudn-v-tailand-i-vetnam (дата обращения 12.09.2020).

55. Филиалы и представительства // Ассоциация выпускников ТПУ. URL: https://alumni.tpu.ru/ content/filiali_i_predstavitelstva.html (дата обращения 12.09.2020).

56. Международное сотрудничество // ИАТЭ НИЯУ МИФИ. URL: http://www.iate.obninsk.ru/node/73 (дата обращения 12.09.2020).

57. НИЯУ МИФИ награжден Орденом Дружбы Социалистической Республики Вьетнам // Национальный исследовательский ядерный университет МИФИ. URL: https:/mephi.ru/content/news/ 1387/129680/?fbclid=IwAR3agVrGJH6B3L7QCCNbsB2g9wJAUhSQPqJ56E8ux4k3aVYR31R2My6M6b Y (дата обращения 12.09.2020).

58. Ядерным специальностям будут обучать 60 студентов из Вьетнама в ДВФУ во Владивостоке // Primamedia.ru. URL: https://primamedia.ru/news/445327/ (дата обращения 12.09.2020).

59. ДВФУ открыл первое представительство российского вуза во Вьетнаме // Дальневосточный федеральный университет. URL: https://www.dvfu.ru/news/international_cooperation/the_university_ opened_the_first_representative_office_of_a_russian_university_in_vietnam/?sphrase_id=1240693 (дата обращения 12.09.2020).

60. В ДВФУ вдвое увеличилось число студентов из Вьетнама // Дальневосточный федеральный университет. URL: https://www.dvfu.ru/news/fefu-news/at_the_university_has_doubled_the_number_of_ students_from_vietnam/ (дата обращения 12.09.2020).

61. Праздник русской культуры провели во вьетнамском представительстве ДВФУ // Дальневосточный федеральный университет. URL: https://www.dvfu.ru/news/international_cooperation/the_festival_of_ russian_culture_held_in_the_vietnamese_representative_office_of_the_university/?sphrase_id=1240693 (дата обращения 12.09.2020). 
62. В ДВФУ подвели итоги XVII-ой Олимпиады по вьетнамскому языку, посвященной 65-летию Победы Вьетнамской народной армии под Дьенбьенфу // Дальневосточный федеральный университет. URL: https://www.dvfu.ru/schools/school_of_regional_and_international_studies/news/in_the_far_eastern_ federal_university_summed_up_the_results_of_the_xvii_th_olympic_games_in_vietnamese_language_ dedicated_to_the_65th_anniversary_of_the_victory_of_the_vietnam_people_s_army_at_dien_bi/ (дата обращения 12.09.2020).

63. Студенты ВИ-ШРМИ приняли участие в симуляции переговорного процесса по формату Комиссии по реке Меконг // Дальневосточный федеральный университет. URL: https://www.dvfu.ru/ schools/school_of_regional_and_international_studies/news/students_of_vi_srmi_took_part_in_the_simulat ion_of_the_negotiation_process_in_the_format_of_the_commission_on_the_mekong_river/ (дата обращения 12.09.2020).

64. ДВФУ расширяет научно-исследовательские связи с Республикой Вьетнам // Дальневосточный федеральный университет. URL: https://www.dvfu.ru/news/fefu-news/fefu_expands_research_ties_with_ vietnam/ (дата обращения 12.09.2020).

65. Научное сотрудничество // Российско-Вьетнамский Тропический научно-исследовательский и технологический центр. URL: http://tropcenter.ru/about/cooperation/index.php (дата обращения 12.09.2020).

66. Специалистов для ведущей нефтегазодобывающей компании Вьетнама планируют готовить в Томском политехе // Национальный исследовательский Томский политехнический университет. URL: https://news.tpu.ru/news/2016/08/05/25664/ (дата обращения 12.09.2020).

67. Томский политех и вьетнамские компании планируют расширять сотрудничество // Национальный исследовательский Томский политехнический университет. URL: https://news.tpu.ru/news/ 2017/08/25/27554/ (дата обращения 12.09.2020).

68. Проекты ТПУ по водоочистке, медицине и подготовке кадров заинтересовали представителей крупнейших компаний Вьетнама // Национальный исследовательский Томский политехнический университет. URL: https://news.tpu.ru/news/2018/10/30/33896/ (дата обращения 12.09.2020).

Поступила 29.09.2020 г. 


\title{
BEST PRACTICES OF RUSSIAN UNIVERSITIES EDUCATIONAL PROGRAMS EXPORT TO THE SOCIALIST REPUBLIC OF VIETNAM
}

\author{
Polina S. Golomidova, \\ polinagolomidova@gmail.com \\ Northern (Arctic) Federal University named after M.V. Lomonosov, \\ 17, Northern Dvina embankment, Arkhangelsk, 163002, Russia
}

Polina S. Golomidova, postgraduate student, head of international student recruitment unit, Northern (Arctic) Federal University named after M.V. Lomonosov.

Relevance. The growing importance of international student migration is associated not only with the increase in the number of international students around the world, but also with the growing political, economic and cultural influence of these processes, as well as with the purposeful activities of exporting countries and universities to promote educational programs abroad. One of the most perspective countries in the sphere of higher education institutions programs' export is the Socialist Republic of Vietnam, which is on the upward trend of outgoing academic mobility. The aim of the article is to present the results of study of the best practices and tools used by Russian universities to attract students from the Socialist Republic of Vietnam. Methodology. Within the framework of the analysis of statistical data of the Center for Sociological Research of the Ministry of Education and Science of Russia, the UNESCO Institute for Statistics, analysis of open sources in the Internet, as well as participant observation within the framework of the author's professional activities, academic and marketing activities were identified, as well as various formats of interaction with students, ALUMNI, Vietnamese and Russian organizations operating in Vietnam. According to the results of the study, it was found that all studied universities use a combination of different practices, diversifying recruitment tools and developing broad scientific and educational cooperation with Vietnam. The study identified the following practices that facilitate the recruitment of Vietnamese students: (1) organizing olympiads for Vietnamese schoolchildren; (2) support for teaching and learning Russian as a foreign language; (3) development of cooperation with universities in Vietnam; (4) development of cooperation with schools in Vietnam, including those in which Russian language is taught; (5) work with university students and alumni from the Vietnam; (6) participation in Russian-Vietnamese interstate training programs. Conclusions. All the studied universities use a complex combination of various tools, without focusing on only one of them. Unique tools for recruiting Vietnamese students are used by the Far Eastern Federal University (representation of the university in Vietnam, development of Vietnamese studies at the university, participation in the activities of the Russian-Vietnamese Tropical Research and Technological Center), Tomsk Polytechnic University (development of cooperation with Vietnamese business companies). A special model is the export of educational services by MEPhI, which trains specialists from Vietnam in the field of nuclear energy. The implementation of this model is due to the industry specifics of the university.

Key words: Export of higher education, recruitment of international students, international student migration, higher education, Vietnam, internationalization.

\section{REFERENCES}

1. Education: outbound internationally mobile students by host region. UNESCO Institute of Statistics. Available at: URL: http://data.uis.unesco.org/ (accessed 3 September 2020).

2. Strategiya uvelicheniya doli Rossii na mezhdunarodnom rynke vysshego obrazovaniya [Strategy for increasing Russia's share in the international higher education market]. RANEPA. Available at: https://www.ranepa.ru/images/docs/nayka/strategy.pdf (accessed 4 September 2020). 
3. Mazzarol T., Soutar G. «Push-pull» factors influencing international student destination choice. International Journal of Education Management, 2002, no. 16 (2), pp. 82-90.

4. Özturgut O. Best practices in recruiting and retaining international students in the U.S. Current Issues in Education, 2013, no. 16 (2). Available at: http://cie.asu.edu/ojs/index.php/cieatasu/article/view/1213 (accessed 4 September 2020).

5. Gok E., Gumus S. International student recruitment efforts of Turkish universities: rationales and strategies. Annual review of comparative and international education. Ed. by A.W. Wiseman. Betnthelem, Bingley, UK, Emerald, 2018. pp. 231-256.

6. Scott J.J. International student mobility: International student recruitment at the University of Saskatchewan. A Thesis Submitted to the College of Graduate and Postdoctoral Studies in Partial Fulfillment of the Requirements for the Degree of Master of Education in the Department of Educational Administration University of Saskatchewan. Saskatoon, 2019. Available at: https://harvest.usask.ca/bitstream/handle/10388/ 12554/SCOTT-THESIS-2020.pdf?sequence=1\&isAllowed=y (accessed 5 September 2020).

7. Melikyan A.V. Vnutrennie faktory rezultativnosti eksporta obrazovaniya v rossiyskikh vuzakh [Internal factors of the effectiveness of export of education in Russian universities]. Voprosy obrazovaniya, 2018, no. 3, pp. 146-179. Available at: https://cyberleninka.ru/article/n/vnutrennie-faktory-rezultativnostieksporta-obrazovaniya-v-rossiyskih-vuzah (accessed 11 September 2020).

8. Vashurina E.V., Vershinina O.A., Gaziyeva Ch.F. Privlechenie inostrannykh studentov $v$ rossiyskie universitety. Prakticheskoye rukovodstvo [Attracting foreign students to Russian universities. Practical guidance]. Yekaterinburg, Ural Federal University Publ., EBS ASV Publ., 2016. 234 p.

9. Otchet o vypolnenii rabot po Kontrolnoy tochke № 45 I-etap marketingovykh issledovaniy mezhdunarodnogo obrazovatelnogo rynka, $\mathrm{v}$ tom chisle razrabotka marketingovykh rekomendatsiy rossiyskim obrazovatelnym organizatsiyam po prodvizheniyu obrazovatelnykh programm na mezhdunarodnom obrazovatelnom rynke [Report on the implementation of work on Control Point No. 45 I-stage of marketing research of the international educational market, including the development of marketing recommendations to Russian educational organizations to promote educational programs in the international educational market]. RANEPA. Available at: https://www.ranepa.ru/images/docs/nayka/otchet-KT45.pdf (accessed 11 September 2020).

10. Ryazantsev S.V., Pismennaya E.E. Migratsionnye plany vetnamskoy molodezhi v kontekste Rossiyskoy politiki privlecheniya obrazovatelnykh migrantov [Migration plans of Vietnamese youth in the context of the Russian policy of attracting educational migrants]. Vetnamskie issledovaniya, 2017, no. 7, pp. $204-211$.

11. Ryazantsev S.V., Pismennaya E.E. Obrazovatelnaya i trudovaya migratsiya vetnamtsev v Rossiyu: tendentsii i potentsial [Educational and labor migration of Vietnamese to Russia: trends and potential]. Vyetnamskie issledovaniya, 2013, no. 3, pp. 65-74.

12. Ryazantsev S.V., Manyiin R.V., Moiseeva E.M., Pinchuk V.N. Migratsiya naseleniya iz Vetnama: sovremennye osobennosti i vozmozhnosti dlya Rossii [Population migration from Vietnam: modern features and opportunities for Russia]. Vyetnamskiye issledovaniya, 2019, no. 2, pp. 29-43.

13. Sokolov A.A. Sovremennaya obrazovatelnaya migratsiya iz Vetnama: vozmozhnosti i vyzovy [Modern educational migration from Vietnam: opportunities and challenges]. YuVA: aktualnye problemy razvitiya, 2017, no. 35, pp. 184-205.

14. Dinh Tkhi Tkhu Khuyen. Istoriya stanovleniya i razvitiya obucheniya russkomu yazyku vo Vetname [History of the formation and development of Russian language teaching in Vietnam]. Pedagogika. Psikhologiya. Filosofiya, 2019, no. 3 (15), pp. 5-13.

15. Mezhdunarodnoe sotrudnichestvo [International cooperation]. Natsionalny issledovatelskiy yaderny universitet «MIFI» (NIYaU MIFI). Obninskiy institut atomnoy energetiki (IATE) [National Research Nuclear University «MEPhI» (NRNU MEPhI). Obninsk Institute of Atomic Energy (IATE)]. Available at: http://www.iate.obninsk.ru/node/73 (accessed 5 September 2020).

16. Spetsialistov dlya vedushchey neftegazodobyvayushchey kompanii Vetnama planiruyut gotovit v Tomskom politekhe [It is planned to train specialists for the leading oil and gas company in Vietnam at the Tomsk Polytechnic Institute]. TPU. Available at: https://news.tpu.ru/news/2016/08/05/25664/ (accessed 11 September 2020).

17. Vetnamskiy gala-fest [Vietnamese gala fest]. Tula State University. Available at: http://tsu.tula.ru/ news/all/9433 (accessed 11 September 2020).

18. V DVFU vdvoe uvelichilos chislo studentov iz Vetnama [FEFU has doubled the number of students from Vietnam]. FEFU. Available at: https://www.dvfu.ru/news/fefu-news/at_the_university_has_doubled_the_ number_of_students_from_vietnam/?sphrase_id=1374225 (accessed 11 September 2020).

19. Sibirskiy grinfild. Prorektor TGU Artem Rykun o 800 inostrannykh studentakh i migratsionnom tsunami [Siberian Greenfield. TSU Vice-Rector Artem Rykun on 800 foreign students and the migration tsunami]. 
Tomskiy obzor. Available at: https://obzor.city/article/617749---sibirskij-grinfild.-prorektor-tgu-artemrykun-o-800-inostrannyh-studentah-i-migracionnom-cunami (accessed 11 September 2020).

20. TGU uchastvuet $\mathrm{v}$ obrazovatelnykh proyektakh vo Vetname [TSU participates in educational projects in Vietnam]. TSU. Available at: http://www.tsu.ru/podrobnosti/tgu-uchastvuet-v-obrazovatelnykh-proektakhvo-vetname/?sphrase_id=248958 (accessed 11 September 2020).

21. 11-y etap dolgosrochnogo obrazovatelnogo proekta «Vuzy Rossii» vo Vetname [11th stage of the long-term educational project «Russian universities» in Vietnam]. Rossiyskiy tsentr nauki i kultury v Khanoe [Russian Center for Science and Culture in Hanoi]. Available at: http://vnm.rs.gov.ru/ru/news/42854 (accessed 12 September 2020).

22. Dolgosrochny obrazovatelny proekt «Vuzy Rossii» [Long-term educational project «Universities of Russia»]. Rossiyskiy tsentr nauki $i$ kultury v Khanoe. Available at: http://vnm.rs.gov.ru/ru/activities/180/ projects/242 (accessed 5 September 2020).

23. DVFU provel olimpiadu po matematike dlya shkolnikov vo Vetname [FEFU held a mathematics Olympiad for schoolchildren in Vietnam]. FEFU. Available at: https://www.dvfu.ru/news/admission/the_university_ held_a_mathematics_contest_for_students_in_vietnam/(accessed 11 September 2020).

24. Predmetnye olimpiady pomogut vetnamskim shkolnikam postupit v DVFU [Subject Olympiads will help Vietnamese schoolchildren to enter FEFU]. FEFU. Available at: https://www.dvfu.ru/news/ international_cooperation/olympiad_will_help_vietnamese_students_to_enroll_at_fefu/ (accessed 11 September 2020).

25. Shkolniki Vetnama poprobovali svoi sily v olimpiade «Okean znaniy» DVFU [Schoolchildren of Vietnam tried their hand at the Olympiad «Ocean of Knowledge» FEFU]. FEFU. Available at: https://www. dvfu.ru/news/international_cooperation/students_of_vietnam_have_tried_their_hand_at_the_olympics_far_ eastern_federal_university/ (accessed 11 September 2020).

26. RUDN uchastvuet $\mathrm{v}$ olimpiadnom dvizhenii vo Vetname [RUDN University participates in the Olympic movement in Vietnam]. RUDN University. Available at: http://www.rudn.ru/media/news/about_rudn/rudnuchastvuet-v-olimpiadnom-dvijenii-vo-vetname (accessed 11 September 2020).

27. V Khanoe sostoyalas Olimpiada RUDN po russkomu yazyku. O rabochem vizite delegatsii Universiteta vo Vetname [In Hanoi, the RUDN University Olympiad in the Russian language took place. On the working visit of the delegation of the University to Vietnam]. Rossiyskiy tsentr nauki i kultury v Khanoe. Available at: http://old.rudn.ru/index.php?pagec=6190 (accessed 12 September 2020).

28. Vizit delegatsii Rossiyskogo universiteta druzhby narodov v ramkakh Dekabrskoy metodicheskoy nedeli v g. Khanoe [Visit of the delegation of the Peoples' Friendship University of Russia in the framework of the December methodological week in Hanoi]. Rossiyskiy tsentr nauki $i$ kultury $v$ Khanoe. Available at: http://vnm.rs.gov.ru/\%20\%20/news/39642 (accessed 11 September 2020).

29. TyumGU gotovit k postupleniyu vetnamskikh abiturientov [TulSU prepares Vietnamese applicants for admission]. TulSU. Available at: https://news.utmn.ru/news/mezhdunarodnaya-deyatelnost/641621/ (accessed 11 September 2020).

30. Komandirovka vo Vetnam [Business trip to Vietnam]. Faculty of Philology, RUDN University. Available at: http://phil.rudn.ru/vietnam_aprel (accessed 11 September 2020).

31. TGU - glavny vuz po testirovaniyu na znanie russkogo yazyka v Khoshimine [TSU is the main university for testing the knowledge of the Russian language in Ho Chi Minh City]. TSU. Available at: http://www. tsu.ru/news/tgu-glavnyy-vuz-po-testirovaniyu-na-znanie-russkog/ (accessed 12 September 2020).

32. Rusisty Politekha: populyarnost russkogo yazyka vo Vetname rastet [Russianists of the Polytech: the popularity of the Russian language in Vietnam is growing]. SPbPU. Available at: https://www.spbstu.ru/ media/news/international_activities/rusite-polytech-popularity-russian-language-vietnam-growing/ (accessed 11 September 2020).

33. TGU razvivayet sotrudnichestvo so shkolami Vyetnama [TSU develops cooperation with schools in Vietnam]. TSU International Students Support Center. Available at: http://studentcenter.tsu.ru/news/тгуразвивает-сотрудничество-со-школами-вьетнама (accessed 11 September 2020).

34. Starsheklassniki iz Vetnama proshli intensiv po russkomu yazyku v TGU [High school students from Vietnam took an intensive course in the Russian language at TSU]. TSU. Available at: http://www.tsu.ru/news/starsheklassniki-iz-vetnama-proshli-intensiv-po-ru/ (accessed 11 September 2020).

35. Komanda TGU i shkola Khayfona vmeste sdelali shag k tsifrovomu obrazovaniyu [TSU team and Haiphong School together took a step towards digital education]. TSU. Available at: http://www.tsu.ru/news/komandatgu-i-shkola-khayfona-vmeste-sdelali-shag-/?nv=on (accessed September 2020).

36. Prepodavateli TPU nachali onlayn-zanyatiya po russkomu yazyku dlya shkolnikov iz Vetnama [TPU teachers have started online Russian language classes for schoolchildren from Vietnam]. TPU. Available at: https://news.tpu.ru/news/2017/05/05/27150/ (accessed September 2020). 
37. TGU uchastvuyet $\mathrm{v}$ obrazovatelnykh proyektakh vo Vyetname [TSU participates in educational projects in Vietnam]. TSU. Available at: http://www.tsu.ru/podrobnosti/tgu-uchastvuet-v-obrazovatelnykh-proektakhvo-vetname/ (accessed 11 September 2020).

38. Dni rossiyskoy kultury i nauki v universitete Bin Zyong vo Vyetname [Days of Russian Culture and Science at Binh Duong University in Vietnam]. SPbPU. Available at: https://www.spbstu.ru/media/news/ international_activities/days-russian-culture-science-binh-zyong-university-vietnam/ (accessed 11 September 2020).

39. Politekh prodolzhaet nauchno-tekhnicheskoe partnerstvo s vuzami Vetnama [Polytech continues scientific and technical partnership with universities in Vietnam]. SPbPU. Available at: https://www.spbstu.ru/media/ news/international_activities/prospects-joint-science-education-center-basis-vielina/ (accessed 11 September 2020).

40. Sankt-Peterburg i Vetnam: itogi sotrudnichestva i plany na budushchee [St. Petersburg and Vietnam: results of cooperation and plans for the future]. SPbPU. Available at: https://www.spbstu.ru/media/ news/international_activities/st-petersburg-vietnam-outcomes-of-cooperation-and-future-plans/ (accessed 11 September 2020).

41. Delegatsiya SPbPU posetila Sotsialisticheskuyu Respubliku Vetnam [SPbPU delegation visited the Socialist Republic of Vietnam]. SPbPU. Available at: https://www.spbstu.ru/media/news/international_activities/ delegation-spbpu-socialist-republic-vietnam/ (accessed 11 September 2020).

42. Prepodavateli Vetnama budut uchitsya v aspiranture i magistrature TGU [Teachers of Vietnam will study in postgraduate and master's programs at TSU]. TSU. Available at: http://www.tsu.ru/news/prepodavatelivetnama-budut-uchitsya-v-aspiranture/ (accessed 11 September 2020).

43. TGU razvivaet sotrudnichestvo s vedushchimi vuzami Vetnama i Laosa [TSU develops cooperation with leading universities in Vietnam and Laos]. TSU. Available at: http://www.tsu.ru/news/tgu-razvivaetsotrudnichestvo-s-vedushchimi-vuzami/ (accessed 11 September 2020).

44. Obrazovatelnye programmy DVFU predstavili vo Vetname [FEFU educational programs were presented in Vietnam]. FEFU. Available at: https://www.dvfu.ru/news/international_cooperation/the_educational_program_of_the_university_introduced_in_vietnam/(accessed 11 September 2020).

45. Rossiyskie, vetnamskie i evropeyskie vuzy budut vmeste gotovit spetsialistov dlya «umnoy» energetiki [Russian, Vietnamese and European universities will together train specialists for smart energy]. TPU. Available at: https://news.tpu.ru/news/2017/09/06/27602/ (accessed 11 September 2020).

46. Sotrudniki VI-SHRMI prinyali uchastie v meropriyatiyakh vo Vetname, posvyashchennykh 100-letiyu Oktyabrskoy revolyutsii v Rossii [VI-SHRMI employees took part in events in Vietnam dedicated to the 100th anniversary of the October Revolution in Russia]. FEFU. Available at: https://www.dvfu.ru/schools/ school_of_regional_and_international_studies/news/the_staff_of_vi_srmi_took_part_in_events_in_vietnam_d edicated_to_the_100th_anniversary_of_the_october_revolution_in_russia_/ (accessed 12 September 2020).

47. Vetnamskie studenty $v$ Rossii populyariziruyut otechestvennuyu kulturu [Vietnamese students in Russia popularize Russian culture]. Available at: http://huunghivietnga.com.vn/news/vshcdpkajoizd-oprgdkpsh-vnloozz-mlmryiyanzzhznryup-lpdfdopvdkkryu-iryishcprnr (accessed 12 September 2020).

48. Konkurs «MISS VYETNAM» [Competition «MISS VIETNAM»]. RUDN University. Available at: http://www.rudn.ru/media/news/about_rudn/konkurs-miss-vetnam (accessed 12 September 2020).

49. Vetnamskiy gala-fest [Vietnamese Gala Fest]. TulGU. Available at: http://tsu.tula.ru/news/all/9433 (accessed 12 September 2020).

50. Traditsionnymi sladostyami, pesnyami i «tantsem s bambukom» v TPU otprazdnuyut Den Vetnama [Traditional sweets, songs and «dance with bamboo» at TPU will celebrate Vietnam Day]. TPU. Available at: https://news.tpu.ru/news/2017/11/03/27877/ (accessed 12 September 2020).

51. Vystavka v DVFU otkryla mesyachnik rossiysko-vetnamskoy druzhby $\mathrm{v}$ Primore [Exhibition at FEFU opened the month of Russian-Vietnamese friendship in Primorye]. FEFU. Available at: https://www.dvfu.ru/news/international_cooperation/exhibition_the_university_opened_the_month_of_russi an_vietnamese_friendship_in_primorye/ (accessed 12 September 2020).

52. Studenty otmetili Den Nezavisimosti Vetnama [Students celebrated the Independence Day of Vietnam]. SPbPU. Available at: https://www.spbstu.ru/media/news/international_activities/students-celebratedindependence-day-vietnam/?sphrase_id=1407867 (accessed 12 September 2020).

53. Ediny den vypusknika vo Vetname [A single graduate day in Vietnam Vietnam]. Rossiyskiy tsentr nauki $i$ kultury v Khanoye. Available at: http://vnm.rs.gov.ru/\%C2\%A0/news/58130 (accessed 12 September 2020).

54. Vizit delegatsii RUDN v Tayland i Vetnam [Visit of the RUDN University delegation to Thailand and Vietnam]. RUDN University. Available at: http://www.rudn.ru/media/news/about_rudn/vizit-delegacii-rudn-vtailand-i-vetnam (accessed 12 September 2020). 
55. Filialy i predstavitelstva [Branches and representative offices]. TPU Alumni Association. Available at: https://alumni.tpu.ru/content/filiali_i_predstavitelstva.html (accessed 12 September 2020).

56. Mezhdunarodnoe sotrudnichestvo [International cooperation]. MEPhI. Available at: http://www.iate.obninsk.ru/node/73 (accessed 12 September 2020).

57. NIYaU MIFI nagrazhden Ordenom Druzhby Sotsialisticheskoy Respubliki Vetnam [MEPhI was awarded the Order of Friendship of the Socialist Republic of Vietnam]. MEPhI. Available at: https://mephi.ru/content/news/1387/129680/?fbclid=IwAR3agVrGJH6B3L7QCCNbsB2g9wJAUhSQPqJ56 E8ux4k3aVYR31R2My6M6bY (accessed 12 September 2020).

58. Yadernym spetsialnostyam budut obuchat 60 studentov iz Vetnama v DVFU vo Vladivostoke [60 students from Vietnam will teach nuclear specialties at FEFU in Vladivostok]. Primamedia.ru. Available at: https://primamedia.ru/news/445327/ (accessed 12 September 2020).

59. DVFU otkryl pervoe predstavitelstvo rossiyskogo vuza vo Vetname [FEFU opened the first representative office of a Russian university in Vietnam]. FEFU. Available at: https://www.dvfu.ru/news/international_ cooperation/the_university_opened_the_first_representative_office_of_a_russian_university_in_vietnam/ ?sphrase_id=1240693 (accessed 12 September 2020).

60. V DVFU vdvoe uvelichilos chislo studentov iz Vetnama [FEFU has doubled the number of students from Vietnam]. FEFU. Available at: https://www.dvfu.ru/news/fefu-news/at_the_university_has_doubled_the_ number_of_students_from_vietnam/ (accessed 12 September 2020).

61. Prazdnik russkoy kultury proveli vo vetnamskom predstavitelstve DVFU [The holiday of Russian culture was held in the Vietnamese representative office of FEFU]. FEFU. Available at: https://www.dvfu.ru/news/international_cooperation/the_festival_of_russian_culture_held_in_the_vietname se_representative_office_of_the_university/?sphrase_id=1240693 (accessed 12 September 2020).

62. V DVFU podveli itogi XVII-oy Olimpiady po vetnamskomu yazyku, posvyashchennoy 65-letiyu Pobedy Vyetnamskoy narodnoy armii pod Dyenbyenfu [FEFU summed up the results of the 17th Olympiad in the Vietnamese language, dedicated to the 65th anniversary of the Victory of the Vietnamese People's Army near Dien Bien Phu]. FEFU. Available at: https://www.dvfu.ru/schools/school_of_regional_and_international_studies/news/in_the_far_eastern_federal_university_summed_up_the_results_of_the_xvii_ th_olympic_games_in_vietnamese_language_dedicated_to_the_65th_anniversary_of_the_victory_of_the_vi etnam_people_s_army_at_dien_bi/(accessed 12 September 2020).

63. Studenty VI-ShRMI prinyali uchastie v simulyatsii peregovornogo protsessa po formatu Komissii po reke Mekong [VI-ShRMI students took part in the simulation of the negotiation process according to the format of the Mekong River Commission]. FEFU. Available at: https://www.dvfu.ru/schools/school_of_regional_ and_international_studies/news/students_of_vi_srmi_took_part_in_the_simulation_of_the_negotiation_proc ess_in_the_format_of_the_commission_on_the_mekong_river/ (accessed 12 September 2020).

64. DVFU rasshiryaet nauchno-issledovatelskie svyazi s Respublikoy Vetnam [FEFU expands scientific research ties with the Republic of Vietnam]. FEFU. Available at: https://www.dvfu.ru/news/fefunews/fefu_expands_research_ties_with_vietnam/(accessed 12 September 2020).

65. Nauchnoe sotrudnichestvo [Scientific collaboration]. Russian-Vietnamese Tropical Research and Technology Center. Available at: http://tropcenter.ru/about/cooperation/index.php (accessed 12 September 2020).

66. Spetsialistov dlya vedushchey neftegazodobyvayushchey kompanii Vetnama planiruyut gotovit v Tomskom politekhe [Specialists for the leading oil and gas company in Vietnam are planning to train at the Tomsk Polytechnic Institute]. TPU. Available at: https://news.tpu.ru/news/2016/08/05/25664/ (accessed 12 September 2020).

67. Tomskiy politekh i vetnamskie kompanii planiruyut rasshiryat sotrudnichestvo [Tomsk Polytechnic University and Vietnamese companies plan to expand cooperation]. TPU. Available at: https://news.tpu.ru/news/2017/08/25/27554/ (accessed 12 September 2020).

68. Proekty TPU po vodoochistke, meditsine i podgotovke kadrov zainteresovali predstaviteley krupneyshikh kompaniy Vetnama [TPU projects on water treatment, medicine and personnel training interested representatives of the largest companies in Vietnam]. TPU. Available at: https://news.tpu.ru/news/2018/ 10/30/33896/ (accessed 12 September 2020).

Received: 29 September 2020. 